Review Article

\title{
Beyond Bullying: Consideration of Additional Research for the Assessment and Prevention of Potential Rampage School Violence in the United States
}

\author{
Evonn Welton, Shernavaz Vakil, and Bridgie Ford \\ Department of Curricular and Instructional Studies, The University of Akron, 132 Zook Hall, Akron, OH 44325-4205, USA \\ Correspondence should be addressed to Evonn Welton; ewelton@uakron.edu and Shernavaz Vakil; svakil@uakron.edu
}

Received 14 April 2014; Revised 28 July 2014; Accepted 19 August 2014; Published 28 August 2014

Academic Editor: David Neumann

Copyright (C) 2014 Evonn Welton et al. This is an open access article distributed under the Creative Commons Attribution License, which permits unrestricted use, distribution, and reproduction in any medium, provided the original work is properly cited.

\begin{abstract}
For approximately 15 years there have been a number of episodes of rampage school violence in elementary/high school and higher education in the United States. Initial responses included implementation of antibullying programs, disciplinary measures, and increased law security measures. As the incidences have continued, it has become apparent that a more collaborative and interdisciplinary approach is needed for prevention. This paper offers a review of research literature as it applies to proposed innovative strategies for collaborative research, prevention, and intervention in the school setting.
\end{abstract}

\section{Beyond Bullying: Additional Considerations in Rampage School Violence}

While modern schools had long been considered to be places of relative safety, this sense of security was dispelled in the late 1990s when a series of rampage shootings occurred in the United States $[1,2]$. Most of these rampage shootings involved youth as perpetrators and children, adolescents, and educators as victims. As a response to these incidences, there are numerous articles and recommendations that have been put forward by educators, psychologists, sociologists, law enforcement, and legislators. Immediately following an incident, the media also offer analyses and suggestions from any number of perspectives.

Among the initial responses to these rampage acts of violence and shootings were environmental changes such as increased security and attempts to remove potential perpetrators through disciplinary measures. The presence of security guards, locked buildings, and shooter drills have become commonplace in today's schools. Disciplinary policies such as zero tolerance for even the most minor indicator of aggressive intent have been developed and implemented [1, 3 , 4]. While these environmental and disciplinary changes may have averted some incidences, rampage acts of violence or shootings have continued suggesting the need for additional strategies. It is noted that the rampage aggression primarily involved shootings; however, an incident on April 9, 2014, involved the use of a kitchen knife [5]. Therefore, it is more appropriate to refer to rampage school violence rather than limit the term to "shooting" or "shootings."

Interpersonal dynamics such as bullying were also examined in an effort to gain insight into the rationale of the perpetrators. Levin and Madfis [4] found that the majority of the shooters had experienced bullying and had been ostracized by their peers prior to the rampage shooting; however, there were also other sources of chronic and acute strain in their lives. This strain came from sources outside of the school setting such as within the family. Levin and Madfis [4] also point out that it takes a very long time for a student to build up to the point of acting out in such a violent manner and early identification may be efficacious for prevention as well as the development of increased prosocial skills.

As these incidences have unfolded, increased and holistic consideration of additional variables outside of the educational setting has been pursued. While Levin and Madfis [4] note the role that chronic strain from a variety of sources may contribute to these incidences, there are additional models and theories not directly related to rampage shootings and violence that are also worth exploring. These theories and methods of intervention were not necessarily developed as 
a response to rampage school violence. For example, attachment dynamics, sensitivity to rejection, and the individual's perception of past, present, and future events may also provide insight into the dynamics leading up to rampage violence $[6,7]$. The influence of social learning theory and group dynamics as it relates to technology should also be considered $[8,9]$. Prevention and intervention strategies such as Response to Intervention [10] and Positive Behavioral Intervention Supports [11] for academic and other behavior problems are currently already established in the educational setting. Bringing together explanations from research outside of education and already established educational strategies may prove to be an innovative and positive method for intervention. Recognizing the need for a synthesis of information has already been put forward by Anderson and Bushman [12] in their discussion of a model of aggression. They advocate the identification of a holistic model of aggression that pulls together components from various domain limited explanations. Similarly, a holistic framework for rampage shootings and violence in the school setting should help educators become familiar with research from psychology, sociology, and criminology and assisting researchers from those disciplines become familiar with already established methods of intervention.

The purpose of this paper is to underscore the need for increased communication and collaboration between educators and researchers as continued attempts to prevent rampage school violence continue. In addition, with this communication, research from areas outside of education can be implemented using currently existing educational models and frameworks. Specifically, "domain specific theories are the stones... awaiting a construction crew to build a much more useful house" [12, page 33]. While the models and theories discussed in this paper are not exhaustive, it does underscore the need for education policy makers to be aware of the wide range of applicable research as they move forward with prevention. This may then serve as an alternative to a zero tolerance/law enforcement model of prevention, offer suggestions for prevention in the school setting, and provide a bridge that proves to be beneficial for all stakeholders.

\section{Rampage School Shootings: History, Definition, and the Role of Prior Experiences}

Despite the recent number of incidences that have occurred since the 1990s, rampage violence and shootings in schools in which children are victims are not necessarily a new phenomenon [2]. Throughout years, incidences have occurred with varying motivations. For example, in 1927, a caretaker planted bombs throughout a school building and killed 45 individuals [13]. Thirty-eight of those individuals were children and another 58 individuals were wounded. The motivations behind the bombing included financial problems and resentment about taxation. Similar to many of the violence incidences/shootings, survivors did not suspect that the caretaker was planning such a tragic action. In fact, one survivor stated that he had seen him earlier that morning and he was "smiling and working on a door" (para. 25). Lavergne [14] identifies the more recent rampage shooting at the University of Texas at Austin in 1966 as our "...introduction to public mass murder and school shootings" (para. 2). Lavergne [14] also identifies the several proposed explanations that followed the shooting including a brain tumor, substance abuse, marital/job problems, and a difficult relationship with his father. Lastly, the incident at Columbine High School seemed to set into motion a rash of rampage violence/shootings that now occurs almost annually in school settings. In each of these incidences, society desires to learn the facts of the situation as well as understand the meaning behind these events [15].

Rampage acts of violence/shootings vary across settings and circumstances. Since the beginning of time, individuals as well as groups have demonstrated aggressive behavior. At times aggression is demonstrated at the individual level, at times by groups. At times aggression is characterized as impulsive and, in other incidences, there is evidence of considerable planning. In order to examine a specific form of aggression, it is necessary to determine a definition and parameters that set it apart from others.

Muschert [2] identifies several different typologies which can be utilized to define and separate motivation and other salient factors. Rampage shootings are defined as those shootings in which there is an "expressive and nontargeted attack on a school or institution" (p.63). Muschert adds further clarification and quotes Newman [16] who defines the parameters as "...the attack takes place in a public location, committed by a former member of the institution, involves multiple victims that are at times symbolic or at times random and that it is the organization rather than the individual victims that are important" [16, page 231].

While by Muschert's [2] definition, rampage shootings are nontargeted, Madfis [1] analyzed information about shootings that were averted and found that many of the potential shooters had in fact targeted specific groups or individuals. Therefore, it cannot always be assumed that victims were simply in the wrong place at the wrong time or that the shooting represents a symbolic attack on the school in general. Instead, the data from Madfis' [1] work suggests that the potential shooters sometimes had very specific individuals, groups, and even sections of the building and times identified so as to provide the most access to the targets. Levin and Madfis [4] also indicate that rampage shooters also act very quickly giving security guards little time to react and emphasize the need for preventative approaches based upon early identification rather than reactive strategies.

It can be stated that rampage acts of violence/shootings are aggressive acts designed to kill more than one individual who are physically found within a specific location. The aggressor may or may not be going after a specific individual or group of individuals; however, in most instances, the location represents something symbolic and/or has some negative memory or emotion associated with it $[2,16]$. There are also rampage acts of violence in many settings and are perpetrated by adults who may demonstrate mental illness, have had chronic or acute life stressors, or perhaps have a political agenda but it is the peer on peer rampage 
violence/shooting that seems to be so perplexing. "In the panicked aftermath of the attack at Columbine High School in 1999, numerous shortsighted policies were designed to satiate the public; reduce the anxieties of teachers, student and parents; and make politicians appear to be protecting us [4, pp. 1240-1241]." As incidences have continued, it has become evident that we need to search for broader explanations and solutions.

\section{Early Experiences}

While it is certainly important to examine the more recent events and antecedents leading up to a rampage school violence/shooting, it is also important to consider the impact of experiences in early childhood. Levin and Madfis [4] noted that at least some of the perpetrators of the school shootings may have had experienced a long history of negativity not just from peers, but also from a difficult home environment. Levin and Madfis [4] identify chronic strain, uncontrolled strain, and acute strain that lead up to the planning and eventual rampage shooting. Long standing conflict within the home and family has been identified as present along with more recent but chronic bullying and harassment in the school setting. Feelings of isolation and lack of social support with an eventual perceived catastrophic event(s) may then move the individual into the planning and eventual implementation phases as Levin and Madfis [4] note. During this last phase, the thinking of the rampage shooter has become fatalistic with a sense that there is "nothing left to lose" [4, page 1237].

Henry [17] also states that these rampage school shootings can be characterized as culminating events that represent a long history of negative interactions. It is important to consider the range of experiences that have contributed to the eventual rampage school shooting. Henry [17] indicates that there are subprocesses of violence involved prior to the culminating rampage aggression and the crescendo can either take the form of an excessively violent act such as rampage shooting or remain at a less violent level. Lastly, Henry [17] states that with an analysis that is interdisciplinary and acknowledges a continuum of intensity, earlier events that either reflect or elicit later violence may potentially be prevented. Operationalizing those earlier events as problematic early attachment and difficult family dynamics and resulting later problems may be helpful for identification of those students who are at risk in the school setting.

Langman [18] developed three different typologies not from identifying commonalities between shooters, but rather from examining their differences. After examining available evidence from ten separate incidences, it was concluded that the shooters fell into three broad categories: those that were psychotic, those that had been traumatized, and those that were psychopathic. While identifying typologies, it was also recognized that not all individuals who have been traumatized or are psychotic or psychopathic go on to become rampage shooters. Therefore, other contributory variables include peer influence, parental figures that had been involved in criminal behavior with firearms, and family structure. Exposure to poor role models and family dysfunction were also identified among the traumatized shooters, “...all three had father figures that had been involved in criminal behavior involving the misuse of firearms and two had had an armed stand-off with police" [18, page 84]. Vossekuil et al. [19] found that $2 / 3$ of the shooters had used firearms obtained from their own homes and in some cases had been given these firearms as gifts.

Consistent with models of chronic and early strain/stressors from outside of the school setting, Leary et al. [6] indicate that attachment style is related to aggression. Specifically, they state that individuals with a fearful or preoccupied attachment style are more likely to become aggressive due to internal conflicts and external blame. The individual both wants and avoids approval from significant others and simultaneously perceives the significant other in a negative light when the approval is not forthcoming and threatened with abandonment. While Leary et al. are referring to adults in intimate relationships, this dynamic may also have a significant influence on children. In the case of rampage school attacks, it is possible that the perpetrators may have a conflict between seeking the approval of peers and authority figures and simultaneously seeing peers and authority figures in a negative light. The real or perceived threat of abandonment established at a young age may then generalize to other adults/peers and result in the culminating rage and aggressive act in the school setting. Rejection sensitivity results in the individual becoming hypervigilant and perhaps misinterpreting ambiguous events as negative and rejecting. The origin of rejection sensitivity may begin in childhood and then last well into adult relationships $[6,20]$. Downey and Feldman [20] further state that rejection sensitivity, when experienced by individuals, may result in behaviors that are detrimental to establishment of positive and satisfying relationships.

While it is beneficial to intervene for feelings of rejection, Twenge and Campbell [21] indicate that narcissism or an unrealistically inflated sense of self is also an important variable when considering how to minimize aggression. Specifically, they state that those with narcissism sometimes perceive rejection where none exists due to heightened sensitivity to threats to their perceived self. While it is possible that there may be objective instances of bullying, a child with narcissistic tendencies may misperceive innocuous or benign situations and become upset. Downey and Feldman [20] concur that rejection may be perceived by some individuals in relatively ambiguous circumstances with resulting overreaction. Twenge and Campbell [21] believe that schools may be better served to deemphasize programs that artificially build self-esteem and develop a more realistic self-concept. They also stress that it becomes very important to emphasize "...empathy, perspective taking, reward striving and mastery instead of dominance, and promote character over popularity" [21, page 271]. Incorporating these concepts into already existing strategies used in the school should be considered.

The above studies discuss issues such as attachment, narcissism, and rejection sensitivity within a population that is typically functioning. If these dynamics are downwardly extended to younger children or individuals with disabilities, the cognitive emotional difficulties may be even further 
exacerbated due to the limited ability to process emotional problems and limited experience with successful resolution to conflict. Sebastian et al. [22] found that individuals with autism spectrum conditions (ASC) recognized when they were ostracized or excluded from groups. The results of their study revealed that an ostracism condition did impact anxiety and need threat; however, it did not impact mood modulation as it did in the controls. They hypothesized that the participants with ASC may not have had the insight necessary to self-report mood state. While the results of this study are mixed, it does indicate that an individual with autism may experience similar reactions to perceived rejection and exclusion as typically developing peers. Bonanno and Levenson [23] provide a comprehensive analysis of those factors implicated in school shootings. Their analysis includes a discussion of the possible contribution that Adam Lanza's social/emotional and family issues may have had on the development of chronic strain. This suggests that schools should also include students with disabilities when providing preventative strategies designed to increase coping and decrease stressors.

\section{Additional Antecedents to the Rampage Shooting}

Bandura [8] noted that much of human behavior is a function of modeling and vicarious learning. Some rampage school shooters have directly observed family members either use or misuse firearms $[18,19]$ as a method of asserting power and dealing with overwhelming feelings. The rapid growth of technology and media has also contributed to the ability to observe the behavior and consequences of others outside of the family setting. It is now possible to witness school shootings and the immediate aftermaths as they occur. In addition, media then often spend days or weeks analyzing and reanalyzing the events and the perpetrator. Once the popular press has devoted a great deal of time to the event, some adolescents post self-made videos on social media sites providing further attention. Anonymous comments posted to the videos sometimes express positive opinions about the video contents and may create a sort of electronic community for students who sympathize or have some sense of commonality with the perpetrators. An individual who otherwise might not ever consider such egregious acts may now feel supported or even encouraged by their anonymous electronic group members. In a study by van Beest et al. [9], it was found that individuals who considered themselves to be in a group and ostracized by another group tended to be more aggressive. Vossekuil et al. [19] found that at least $2 / 3$ of the shooters had been encouraged in some way by others even though ultimately they acted alone. Therefore, it is possible that social modeling and a sense of belonging to an anonymous group that has a perceived sense of injustice may encourage such acts either directly or indirectly and increase the probability of an individual demonstrating overtly aggressive and destructive behavior.

For the individual who very possibly has a history of rejection, dysfunctional family challenges, and a sense of fatalism, the prospect of notoriety and infamy may be appealing. It is not only a function of modeling behavior observed in others, but also an effort to establish meaning to their own lives and perhaps communicate indirectly with the outside group who also are experiencing similar feelings of disenfranchisement. Bonanno and Levenson [23] state that rampage shooters often fail to establish meaningful interpersonal peer relationships and that adds to the chronic strain as identified by Levin and Madfis [4].

Behavior can be reinforced through social attention [24] and the individuals who may become future rampage perpetrators may have not had a positive history of social attention for prosocial or productive behaviors in the school or home setting and from significant adults. Nonetheless, they are still driven by a need for social attention, coupled with their feelings of hostility, alienation, and rejection. Therefore, the act of rampage violence satisfies both the need to act out against the perceived rejection and gain notoriety for this act and even perhaps feel they are bringing attention to their plight and the plight of others like them. The intended message, whether to selected individuals or other members of a disenfranchised group, may be that the shooter is "more powerful and important than you thought" [4, page 1240].

Those targeted in this "communication" may be those who are perceived to have withdrawn their approval/positive reinforcement and thus reestablish some form of connection. Because of their fatalistic mindset just prior to the incident, it may not matter to them that they will likely not be present to observe the attention nor that this behavior is not going to reestablish positive feelings. The individual may also feel that once the event has occurred, they will be able to avoid all further experiences of rejection and abandonment so an element of suicidal ideation or intention may also be eliciting the extreme nature of the behavior. Some of the shootings have involved suicide at the end of the massacre and Bonnano and Levenson [23] point out that many of the shooters had previous attempts at suicide as well as histories of severe depression.

\section{5. "Alia Iacta Est" or the Decision Has Been Made}

"Alia iacta est" were the words that one of the school shooters wrote on his arm just prior to an incident of school violence in December, 2013 [25]. This phrase is Latin for "the die is cast" and is attributed to a comment made to Julius Caesar as he led his army across the Rubicon. When this phrase is used, it can be interpreted as that the decision has been made and there is no changing one's mind. While some may consider that the statement refers to the impending deed, it may serve a broader purpose and also refer to the inevitable outcome for the perpetrator. Once the aggressive act is committed, their lives as they once knew it are over forever. It can also potentially be interpreted as essentially a self-destructive statement whether it ends in physical death or not. It further exemplifies the potentially fatalistic mindset of the perpetrators. Just prior to the event, the individual may be feeling as if this was destined to happen and alternative options are no longer available. The past has taught the person 
that life is negative and hurtful and there will likely be no future or not one that is pleasant.

Time Perspective Theory [7] also has benefit for both understanding the thinking of those at risk and understanding the potential intervention strategies. Zimbardo and Boyd [7] indicate that an individual's perspective of time has significant influence on decision making processes. They categorize individuals and their decisions into those that rely primarily on past events, those that consider present factors, and those that primarily consider future consequences for decision making. They then further subdivide the categories. The past orientation is divided into a perspective that focuses on positive versus negative events. The present orientation may focus on hedonistic/pleasure seeking contingencies versus fatalistic ones that emphasize a lack of personal control. The future perspective is defined as one that emphasizes goal driven behavior versus transcendental/spiritual outcomes.

Zimbardo and Boyd's [7] work may then be considered in conjunction with other explanations for behavior. For example, the individual who has developed a fearful attachment may not only aggress toward those perceived as rejecting as an act of revenge, but also consider that the future will likely be negative and therefore develop a very fatalistic sense of the present. Issues of life purpose and meaning and the impact of ostracism also interface with Time Perception Theory. Specifically, a history of rejection or ostracism can also impact the perception one has of life's meaning or sense of purpose [26]. Stillman et al. found that social exclusion was related to a perceived lack of meaning in one's life. Considered within the framework of Time Perspective Theory, it can be stated that negative past experiences then influence the perception of the future as meaningless and without purpose as well as perhaps a sense of loss of control over present events (fatalistic). Taken in combination, these beliefs about one's life and the impact of chronic and acute stressors [4] may then result in the finalized decision to perpetrate a rampage shooting. Like many who engaged in self-destructive or externalized aggressive behavior, fear of consequences would have little impact as the future is already perceived as likely negative or even nonexistent [27].

A fatalistic mindset as described by Zimbardo et al. [27] is common and even encouraged in combat and actually may contribute to the effectiveness of a soldier. Specifically, the soldier has no fear because to have fear means they need to believe there is a future that may be lost. If one does not believe a future exists, then what is there to fear? For an individual considering an aggressive act directed toward a school, they have already made their decision to aggress toward the perceived origin of their pain and perhaps those that they believe have stolen their future from them. In most cases, it would also appear that they likely have made a decision to die in that place either by their own hand or by the hand of law enforcement. Zimbardo and Boyd [7] specifically note that this present fatalistic mindset may have been at the core of the Virginia Tech incident in which thirty-two students were killed. Twenge et al. [28] echo a similar conclusion and state that simply hearing a prediction that exclusion may occur, even in the distant future, may result in aggression. This suggests that a perception of the future as hopeless may contribute to acts of rampage shootings. These maladaptive time perspectives may serve to decrease the self-regulatory mechanisms that would otherwise be in place if the individual has a more positive sense of the future, feared consequences, and believed that there were options available in the present.

As Levin and Madfis [4] found, the path to this level of hopelessness does not happen suddenly nor is it likely that it is attributable to a single or recent event. Zimbardo et al. [27] describe how an individual's perception of the past, present, and future can be formed by experiences and may also result in eventual posttraumatic stress disorder (PTSD). The individual with PTSD has experienced either a series of chronic stressors or perhaps one very impactful event. The individual then develops symptoms of PTSD that include behaviors and feelings such as anxiety and possible dissociative experiences, decreased interest in preevent pleasurable events, and feelings of alienation. The individual may also be excessively irritable, aggressive, or self-destructive. The individual with PTSD may also have distorted or negative beliefs about themselves and distortions regarding blame [29]. Thus, the individual may feel hopeless with a distorted sense of reality and inner feelings of rage. Because of rejection sensitivity and PTSD, an event that might otherwise be minor or ignored by someone else is enough to elicit the resulting tragedy. Levin and Madfis [4] note that it is the presence of an acute stressor that is often the trigger for the event.

While the person may have had very intense feelings of rage and sadness, by the time the individual is ready to commit the act, the individual may be in a cognitively deconstructed state. Twenge et al. [30] state that chronic feelings of emotional distress and pain eventually result in numbness and a certain detachment from real world events and consequences. They add that this deconstructed state can be related to social exclusion or rejection. This feeling of detachment also results in elimination or minimization of natural feelings of fear at the potential consequences and may be related to the present fatalistic time perspective identified by Zimbardo and Boyd [7]. The individual who is about to act out is cut off from their own instinctive feelings of selfpreservation and "...The die is cast." Zimbardo and Boyd add that the present fatalistic state may have contributed to the shootings at Virginia Tech in 2007. Vossekuil et al. [19] indicate that the shooters do often demonstrate behavior that has come to the attention of others and sometimes announce their plans to a peer. Unfortunately, it is rare that the peer shared the danger with an adult.

It has been over fifteen years since the shootings at Columbine High School and significant and contributory research into the etiological factors contributing to rampage shootings in schools has occurred from multiple disciplines. While a significant body of literature exists, connecting that body of literature to existing educational intervention strategies such as Response to Intervention and School-Wide Positive Behavioral Intervention and Support will hopefully serve as an additional method in order to avert future tragedies. 


\section{Prevention of Rampage Shootings in the School Setting, Response to Intervention, and School-Wide Positive Behavioral Intervention}

Efforts to prevent and avert rampage school shootings and violence have included addressing interpersonal dynamics such as bullying in the educational setting. Disciplinary strategies such as zero tolerance and the increased presence of security have also received emphasis [4]. While virtually all districts now have safety drills, a crisis plan, and conduct threat assessments when there is a suspicion of imminent danger [23] there are additional issues as noted in the above research literature that warrant attention. Sparks [31] noted that while 45 schools have antibullying policies, only 24 have a broader approach that addresses all aspects of the students' social-emotional well-being and perhaps less consider the multiple variables that may be contributing to the motivation behind a rampage act of school violence or shooting. In addition, the implementation of antibullying programs without careful examination of the efficacy of such programs at minimum may render them ineffective and at maximum serve to exacerbate the problem. Jeong and Lee [32] stated that students who have a propensity to bully may actually learn new techniques from programs that stress knowledge about bullying and call for increased attention to the bully/victim dynamics and relationships.

Levin and Madfis [4] recommend addressing bullying but also implementing strategies to minimize the long term stressors that eventually contribute to the culminating rampage violence or school shooting. As the above literature notes, these chronic stressors are not only found in the school setting but may also include family issues. In addition, Bonanno and Levenson [23] call for the creation of a climate of safety. Other issues such as minimizing narcissism and encouraging a positive future perspective may also prove beneficial based upon the research included in this paper.

A connection between these findings and a method for implementation in the school setting is necessary. Response to Intervention is a currently existing model and strategy that can address these and other contributory factors in the school setting. In addition, the Response to Intervention model is currently utilized at all levels and therefore can address stressors that begin in early childhood and long before the time that the student may enter the planning phase as a preventative strategy.

Response to Intervention is a multitiered framework that matches supports and intervention to student needs [33]. It was initially developed as a method of preventing and/or intervening for children at risk for academic failure and to prevent a child from becoming so far behind that identification and testing for special education became necessary. While the initial focus of the model has been on academic/literacy skills, the model also can be utilized to address proactive problem solving approaches for social, emotional, and environmental factors which influence behaviors in schools [10]. School-Wide Positive Behavioral Intervention and Supports, an essential aspect of Response to Intervention, is a process aimed at preventing inappropriate behaviors and replacing them with appropriate behaviors across the three tiers identified by the Response to Intervention model.

According to Kerr and Nelson [10] components essential to effective Response to Intervention should include a shared vision, leadership for monitoring and plan evaluation, and collaboration and data based evaluation. Applied to issues of rampage school shootings or violence, it is important that all stakeholders have a commitment to the interventions and participate in monitoring to determine efficacy.

Three "tiers" or levels make up the Response to Intervention model. Tier 1 is a system wide intervention designed for the general school population. Given the above-mentioned variables, this might include school-wide strategies that assist teachers with an understanding of the necessity to reduce stressors and utilize conflict resolution [4] for problem solving and system wide antibullying programs would be considered to be within this tier.

Tier I may also serve to implement strategies that help students build a concept of a positive future as identified by Zimbardo and Boyd [7] and Zimbardo et al. [27]. Increased emphasis on collaborating with community businesses and universities to address career possibilities may also be helpful. District wide strategies that seek to engage parents and caregivers in the school community are also important. Development of a positive school climate is the focus of a Tier I intervention such that the school is considered a safe and supported place for learning. Characteristics of a positive school climate include fairness, equity, and caring $[34,35]$. This is consistent with the Twenge and Campbell [21] recommendation of increasing an emphasis on programs that enhance self-esteem based upon a realistic self-concept. Improving coping skills when faced with necessary but critical feedback could also be addressed on a system wide level.

Tier I offers the opportunity to incorporate large scale strategies to positively impact an entire school culture. Strategies may include but are not limited to professional development activities for teachers, all school programs, projects, and art activities. Districts adopt these interventions at a district or perhaps building level and as Lehr [34] also emphasizes, identification of key stakeholders including all building/district personnel and parents is important. At this level, all students are included and therefore the possibility of having an at-risk student "fall through the cracks" is minimized. While there is no formal individual testing involved, everyone is aware of the goals and objectives and can note if a particular student or group of students do not seem to be responding to this level. If implemented with fidelity, schools can identify students unable to succeed with Tier 1 interventions and need additional support to succeed [36].

When, during these large scale interventions, individual or groups of students with particular concerns emerge, the teachers should be able to refer to the school counselor or school psychologist so that small groups might be established. There may be smaller groups of students who are in need of a chance to work through specific feelings about rejection or other pertinent experiences. Tier II interventions may 
also focus on small group social skills instruction, problem solving skills, group counseling, or mentoring programs taken for evidence based practices and are closely monitored to meet specific student needs. Discussion of social modeling and the dangers of on-line or group affiliations could be discussed here. Perhaps the at-risk students would develop a face to face social network such that they do not feel disenfranchised and reliance upon negative on-line communities is eliminated. Some districts collaborate with outside child and adolescent counseling agencies that may also help with these activities. Appropriate parent involvement and permission would also be obtained for the Tier II students as needed. For example, there are formal assessments such as The Ostracism Experiences Scale for Adolescents [37] that may be administered and may require parental permission. The interventions implemented in Tier II can be very different so that specific instruments would need to be identified depending upon the focus of the intervention. Also, there is no requirement that any formal assessment is administered in this tier.

The focus of Tier II may also revolve around the establishment of rapport and trust. Bonanno and Levenson [23] recommend developing a climate in which students can trust adults should they need to report a student. Students in small group Tier II settings may feel more comfortable sharing sensitive information about any number of issues and therefore are more likely to share if they become of another student's plan for a shooting or other externally or internally destructive behavior.

Tier III of Response to Intervention is focused upon intensive interventions for high risk students. This may involve individual discussions with the student by a school counselor or outside referrals for individual or family counseling. It may also involve focused and individualized programs for problem solving/social skills and coping strategies. Communication and collaboration with the family, school, and outside professionals for a wrap-around service model in which all stakeholders communicate and work together toward the same goal are especially important [38].

If a student continues to demonstrate behaviors and other indicators of concern, the last step after Tier III is a referral in order to determine eligibility for special education services. If determined to be eligible, the student will be provided with an Individualized Education Program (IEP) designed to meet individual goals. In addition to providing individualized strategies, special education services provide close monitoring and communication, thus serving as an additional method for preventing severe problems in the school setting. It should be noted that while Response to Intervention is a regular education initiative, students with disabilities would be included to the extent possible in these programs. When more individually focused strategies are implemented, it would be necessary to possibly include them on the IEP. It should be noted that there are specific requirements for special education program eligibility and it is up to the school team to determine eligibility and appropriate services.

One such bridge and mechanism for identification of the elements of Response to Intervention as it applies to rampage school violence/shootings is the concept of School-Wide Positive Behavioral Interventions and Support. School-Wide Positive Behavioral Interventions and Support is not a defined or limited method of behavioral intervention. Rather, it is a collection of research based practices for behavioral improvement and development of prosocial behavior. School-Wide Positive Behavioral Interventions and Support also shifts the focus of behavioral interventions being implemented individually to a school-wide organizational context [39]. Enhanced procedures and systems using data are implemented to guide decisions related to behavior problems. It also emphasizes environmental changes and the development of prosocial skills rather than relying upon a disciplinary model [39]. Effective School-Wide Positive Behavioral Interventions and Support necessitates schools to establish universal positive behavioral expectations which are taught to both students and staff. Essential to School-Wide Positive Behavioral Interventions and Support is the systematic use of evidence based practices focusing on all three tiers of intervention. A study by Bradshaw et al. [11] supports the efficacy of School-Wide Positive Behavioral Support for behavioral improvement in children. Additionally, implementing School-Wide Positive Behavioral Interventions and Support requires schools to not only focus on the knowledge and skills needed for schools to meet the needs of all students but also include appropriate dispositions from a culturally responsive perspective. This allows for optimum collaboration with school professionals, the community, and parents.

In summary, mechanisms such as Response to Intervention and School-Wide Positive Behavioral Interventions and Support have been in place for several years to address the needs of students with and without identified social/emotional/behavioral needs. Educators continue to collaborate and strive toward improvement in school climate and culture so that the educational experience is positive and promotes growth. While these efforts have been laudable, it would seem that a stronger link between the available research on rampage school shooters and inclusion of these variables in such programs would be beneficial. It would thus allow for a broader range of proactive and preventative services and strategies rather than focusing upon limited strategies such as zero tolerance and reliance upon law enforcement/security.

\section{Conclusion}

Despite wide spread media coverage, disciplinary policies, and increased law enforcement/security, rampage school shootings continue annually. Clearly, there is a need for continued research and proactive intervention in the educational setting in order that as many of these incidences as possible are prevented. Recognizing the need to intervene at a very early level and also regarding issues that may not be obviously related to the rampage incidences such as family dysfunction or perception of one's future is very important for consideration. Levin and Madfis [4] and Twenge and Campbell [21] note that it is important to address chronic stressors, improve coping mechanisms, and encourage a realistic self-concept. 
This paper takes those recommendations as well as others and offers a mechanism for implementation.

Mechanisms for intervention such as Response to Intervention and School-Wide Positive Behavioral Interventions and Support that proceed in a systematic and positive manner are already in place. Further research is also necessary to determine if inclusion of these factors and early efforts at prevention are effective using these models in the school setting. In addition, work needs to be done in the area of development of programs and activities that specifically address these factors so that they are useful educators and developmentally appropriate for children. This paper is hopefully an initial step in combining perspectives from a number of disciplines so that strategies appropriate for the school setting can be developed and implemented.

\section{Conflict of Interests}

The authors declare that there is no conflict of interests regarding the publication of this paper.

\section{References}

[1] E. Madfis, The Risk of School Rampage: Assessing and Preventing Threats of School Violence, Palgrave McMillan, New York, NY, USA, 2014.

[2] G. Muschert, "Research in school shootings," Sociology Compass, vol. 1, pp. 60-80, 2007.

[3] P. J. Hirschfield and K. Celinska, "Beyond fear: sociological perspectives on criminalization of school discipline," Sociology Compass, vol. 5, no. 1, pp. 1-12, 2011.

[4] J. Levin and E. Madfis, "Mass murder school and cumulative strain: a sequential model," The American Behavioral Scientist, vol. 52, no. 9, pp. 1227-1245, 2009.

[5] C. Carter, P. Courson, and P. Brown, "Four school stabbing victims in critical condition ; teen suspect charged as adult," CNN Justice, 2014, http://www.cnn.com/2014/04/09/justice/ pennsylvania-school-stabbing/.

[6] M. Leary, J. Twenge, and E. Quinlivan, "Interpersonal rejection as a determinant of anger and aggression," Personality and Social Psychology Review, vol. 10, no. 2, pp. 111-132, 2006.

[7] P. Zimbardo and J. Boyd, The Time Paradox, Free Press, New York, NY, USA, 2008.

[8] A. Bandura, Social Learning Theory, Prentice Hall, Englewood Cliffs, NJ, USA, 1977.

[9] I. van Beest, A. Carter-Sowell, E. van Dijk, and K. Williams, "Groups being ostracized by groups: is the pain shared, is recovery quicker and are groups more likely to be aggressive?" Group Dynamics, vol. 16, pp. 241-254, 2012.

[10] M. Kerr and M. Nelson, Strategies for Addressing Behavior Problems in the Classroom, Pearson, 6th edition, 2010.

[11] C. P. Bradshaw, T. E. Waasdorp, and P. J. Leaf, "Effects of schoolwide positive behavioral interventions and supports on child behavior problems," Pediatrics, vol. 130, no. 5, pp. el136-el145, 2012.

[12] C. A. Anderson and B. J. Bushman, "Human aggression," Annual Review of Psychology, vol. 53, pp. 27-51, 2002.

[13] S. Bomboy, "Huge school bombing in 1927 puts Sandy Hook in context," Constitution Daily, 2012, http://blog.consti- tutioncenter.org/2012/12/mass-school-bombing-in-1927-putssandy-hook-in-context/.

[14] G. Lavergne, "The legacy of the Texas tower sniper," The Chronicle of Higher Education, vol. 53, no. 34, pp. 1-4, 2007.

[15] J. Schildkraut and G. Muschert, "Media salience and the framing of mass murder in schools: a comparison of the columbine and sandy hook massacres," Homicide Studies, vol. 18, pp. 23-43, 2014.

[16] K. Newman, Rampage: The Social Roots of School Shootings, Basic Books, New York, NY, USA, 2004.

[17] S. Henry, "School violence beyond columbine: a complex problem in need of an interdisciplinary analysis," American Behavioral Scientist, vol. 52, no. 9, pp. 1246-1265, 2009.

[18] P. Langman, "Rampage school shooters: a typology," Aggression and Violent Behavior, vol. 14, no. 1, pp. 79-86, 2009.

[19] B. Vossekuil, M. Reddy, and R. Fein, “ The Secret Service's safe schools initiative," Education Digest, vol. 66, p. 10, 2001, http:// web.b.ebscohost.com.lib.ezproxy.uakron.edu:2048/ehost/pdfviewer $/$ pdfviewer?vid=54\&sid=8ccca365-d65d-49bd-ad7a9 falfa6adfbd\%40sessionmgrl15\&hid $=123$.

[20] G. Downey and S. I. Feldman, "Implications of rejection sensitivity for intimate relationships," Journal of Personality and Social Psychology, vol. 70, no. 6, pp. 1327-1343, 1996.

[21] J. M. Twenge and W. K. Campbell, “'Isn't it fun to get the respect that we're going to deserve?" Narcissism, social rejection, and aggression," Personality and Social Psychology Bulletin, vol. 29, no. 2, pp. 261-272, 2003.

[22] C. Sebastian, S. Blakemore, and T. Charman, "Reactions to ostracism in adolescents with autism spectrum conditions," Journal of Autism and Developmental Disorders, vol. 39, no. 8, pp. 1122-1130, 2009.

[23] C. Bonanno and R. Levenson, "School shooters: history, current theoretical and empirical findings, and strategies for prevention," Sage Open, vol. 4, no. 1, pp. 1-11, 2014.

[24] P. Alberto and A. Troutman, Applied Behavior Analysis for Teachers, Pearson, Upper Saddle River, NJ, USA, 9th edition, 2012.

[25] E. Dockterman, "Arapahoe High School shooter wrote plans on his arm," Time, 2013, http://nation.time.com/2013/12/17/karlpierson-arapahoe-school-shooter-colorado-wrote-plans-on$\mathrm{arm} /$.

[26] T. F. Stillman, R. F. Baumeister, N. M. Lambert, A. W. Crescioni, C. N. DeWall, and F. D. Fincham, "Alone and without purpose: life loses meaning following social exclusion," Journal of Experimental Social Psychology, vol. 45, no. 4, pp. 686-694, 2009.

[27] P. Zimbardo, R. Sword, and R. Sword, The Time Cure: Overcoming PTSD with the New Psychology of Time Perspective Therapy, Jossey-Bass, San Francisco, Calif, USA, 2012.

[28] J. M. Twenge, R. F. Baumeister, D. M. Tice, and T. S. Stucke, "If you can't join them, beat them: effects of social exclusion on aggressive behavior," Journal of Personality and Social Psychology, vol. 81, no. 6, pp. 1058-1069, 2001.

[29] American Psychiatric Association, Diagnostic and Statistical Manual of Mental Disorders, American Psychiatric Publishing, Arlington, Va, USA, 5th edition, 2013.

[30] J. M. Twenge, K. R. Catanese, and R. F. Baumeister, "Social exclusion and the deconstructed state: time perception, meaninglessness, lethargy, lack of emotion and self-awareness," Journal of Personality and Social Psychology, vol. 85, no. 3, pp. 409423, 2003. 
[31] S. Sparks, "Social-emotional needs entwined with students' learning, security," Education Week, http://www.edweek.org/ ew/articles/2013/01/10/16environment.h32.html.

[32] S. Jeong and B. H. Lee, "A multilevel examination of peer victimization and bullying preventions in schools," Journal of Criminology, vol. 2013, Article ID 735397, 10 pages, 2013.

[33] J. Wheeler and D. Richey, Behavior Management: Principles and Practices of Positive Behavior Supports, Pearson Prentice Hall, Columbus, Ohio, USA, 3rd edition, 2013.

[34] C. Lehr, "Positive school climate: Information for educators," in Helping Children at Home and School II: Handouts for Families and Educators, 2004, http://www.nasponline.org/communications/spawareness/schclimate_ho.pdf.

[35] N. M. Haynes, C. Emmons, and M. Ben-Avie, "School climate as a factor in student adjustment and achievement," Journal of Educational and Psychological Consultation, vol. 8, pp. 321-329, 1997.

[36] A. M. Sorrells, H. J. Rieth, and P. T. Sindelar, Critical Issues in Special Education Access, Diversity, and Accountability, Pearson Education, Boston, Mass, USA, 2004.

[37] R. Gilman, A. R. Carter-Sowell, C. N. DeWall, R. E. Adams, and I. Carboni, "Validation of the ostracism experience scale for adolescents," Psychological Assessment, vol. 25, no. 2, pp. 319330, 2013.

[38] L. Eber, The Art and Science of Wraparound: Completing the Continuum of Schoolwide Behavioral Support, Forum on Education at Indiana University, Bloomington, Ind, USA, 2003.

[39] A. Cohn, "Positive Behavioral Supports: Information for Educators," NASP Resources: Helping children achieve their best. At home. In school. In life, http://www.nasponline.org/ resources/factsheets/pbs_fs.aspx. 

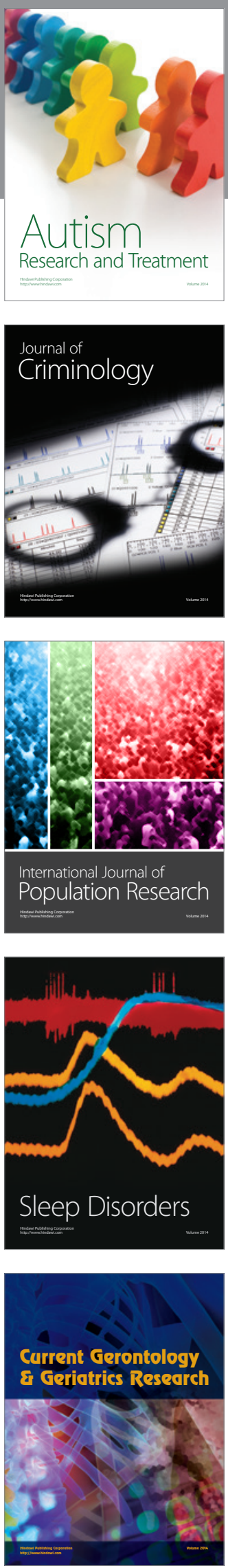
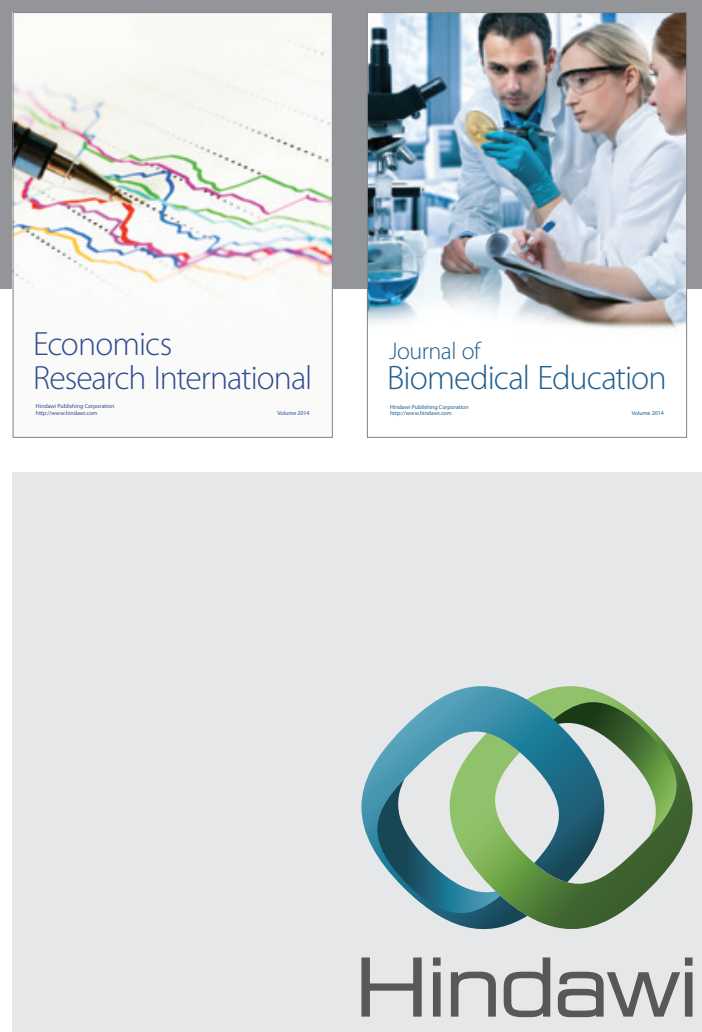

Submit your manuscripts at

http://www.hindawi.com
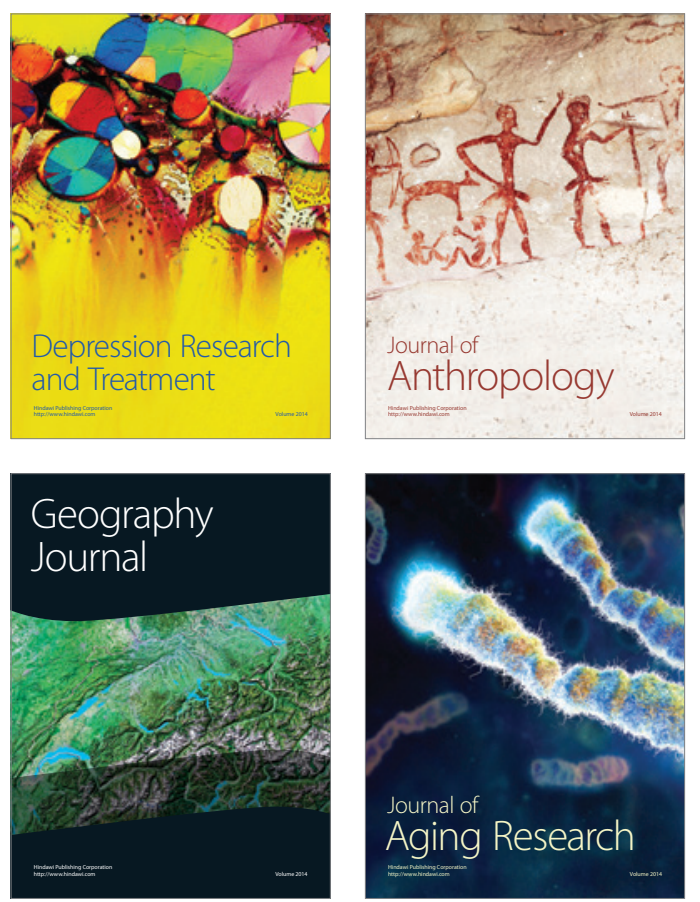
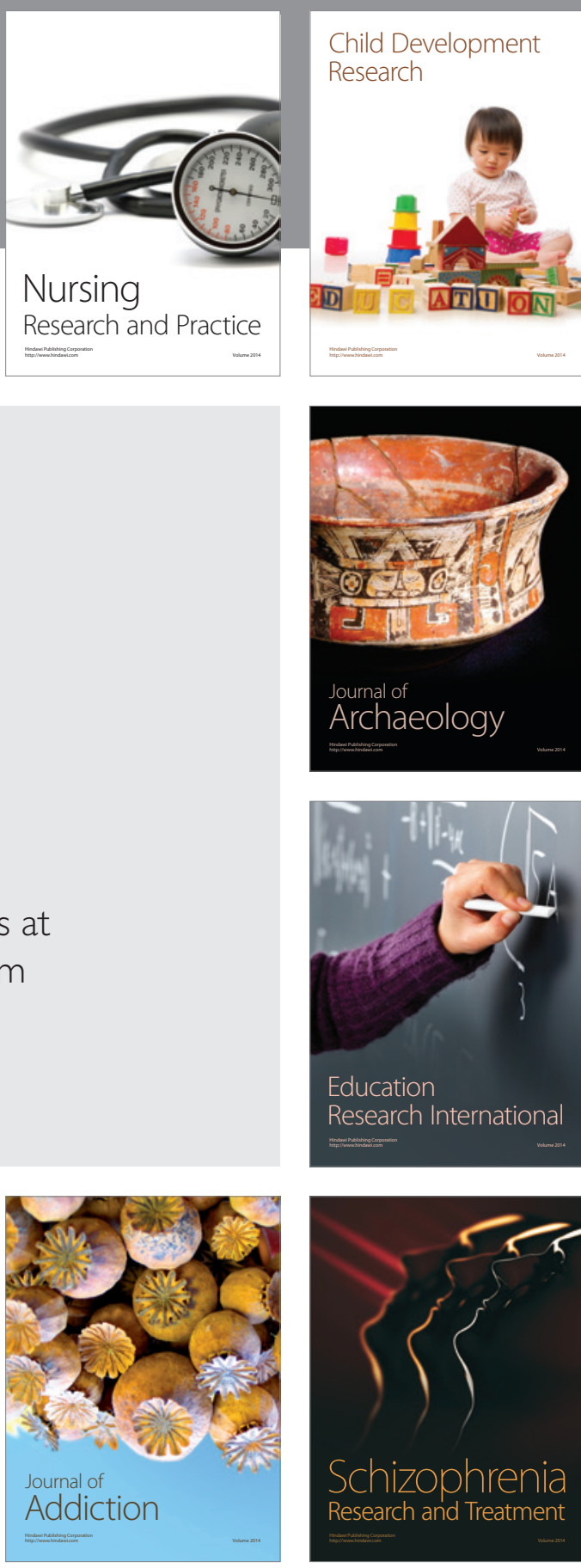

(D)
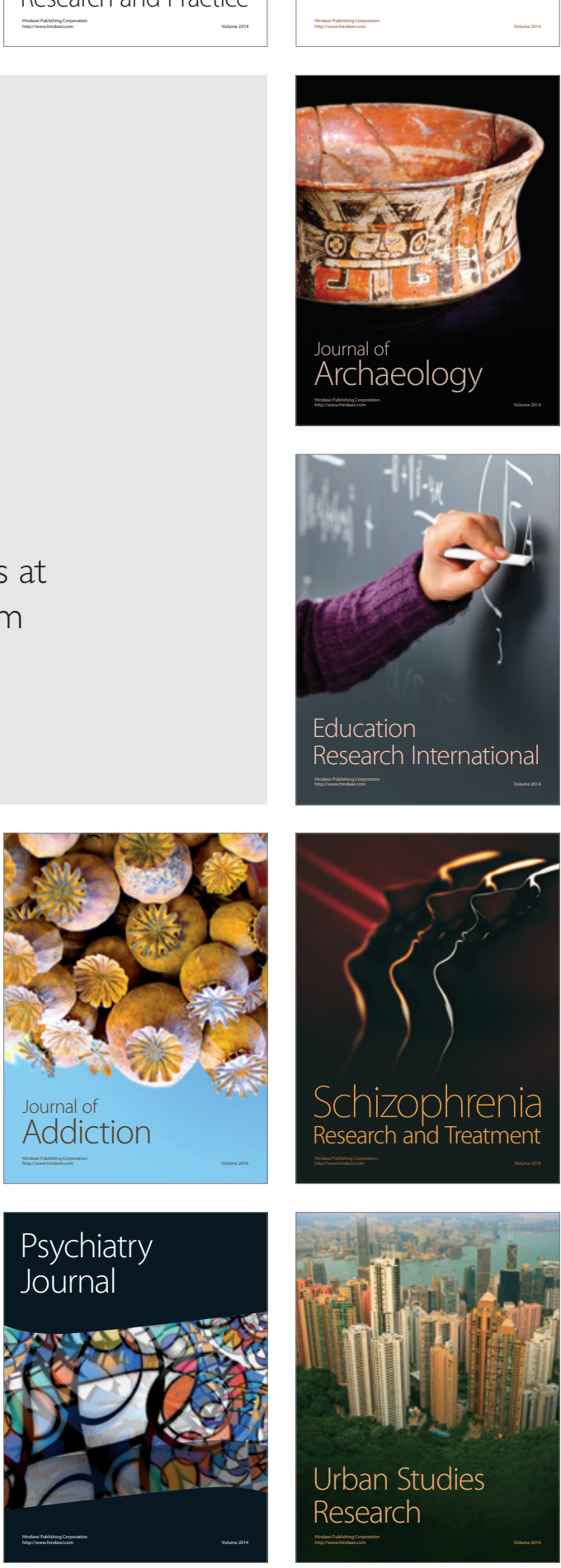